\title{
What are the hospitals doing?
}

\author{
JoHN DUNwOODY \\ M.B., B.S.
}

\section{Director General of Action on Smoking and Health}

THE last few years have shown marked changes in public attitudes towards smoking. No longer is indiscriminate smoking in public places considered generally acceptable, and increasing pressures, not only from non-smokers, have been built up to extend non-smoking areas. For example, public opinion polls show that a considerable majority of both smokers and non-smokers welcome more nonsmoking accommodation on public transport. Thus we have seen this pressure resulting in increasing provision for the non-smoker on buses and trains, on airliners and in cinemas and in other places of entertainment.

A.S.H. feels that of all the places to which the public have access where smoking should be limited and discouraged, the hospital is perhaps the most important. The role that the hospital has to play is to set an example not only to patients and visitors but to the community as a whole. A conference on this subject sponsored by A.S.H. just over a year ago resulted in a number of recommendations being circularized to hospital authorities throughout the United Kingdom. This advice was circularized some months after the Department of Health had issued their Memorandum on Smoking in Hospitals.

A continuing follow-up in the hospital service has shown that many hospitals have taken effective action to limit smoking by in-patients to a reasonable level, to discourage staff from smoking at all in areas accessible to patients, and not to allow smoking by out-patients and visitors. A considerable number of hospitals no longer sell cigarettes on the premises and the open display of tobacco products is now becoming unusual.

Nevertheless, there is a very great contrast between what some hospitals do and the inactivity of others. For example, while in some hospitals there have been very marked limitations of smoking by staff and patients for a considerable number of years, there is at least one chest hospital which, less than a year ago, took the view that to make any rules which would be unacceptable would be idiotic, the more especially because 'a lot of patients came into this hospital to die here'. It is precisely this attitude in specialist units that still confuses very many patients as to whether the doctors really mean what they say when they talk about cigarette induced desease.

\section{Discussion}

DR. BALL: We have not yet covered a very important field, which is the question of medical education and cigarette smoking. The DHSS have stated that they are willing to give to medical students leaving medical school a booklet by Dr Fletcher and Dr Horn on Smoking and Health which is a very good summary. It would be interesting to hear what other people have done or the problems they have had in their own experience either with individual patients such as Dr Handel has had, or in the hospital scene.

Dr J. W. Paterson (Brompton Hospital): Why have British Airlines been so resistant to introducing nosmoking areas?

DR J. Dunwoody (Director General, ASH): The British Airlines have been extraordinarily resistant, it is true. They have responsibility of management of day-today affairs and the provision of non-smoking accommodation is considered to be one of these. ASH started making approaches to them about 2 years ago and got absolutely negative replies. There were a vast series of reasons why they could not do anything. We were also in fact writing to other airlines on the same subject and also gathering information from around the world. We discovered at that time there was, in America, on some of the domestic airlines in particular, very considerable provision for non-smokers. We used this as an example and fortunately at the same time TWA and PAN-AM started to make provision on their international services for non-smokers which was being used as a selling point in their advertisements. With this sort of build up and the change in the climate of opinion here, it has resulted now in some shift on the part of British airlines. The progress is not startling, we have still got a long way to go, but BEA are now beginning to make some provision on some services for non-smokers and BOAC are trying to allocate a certain area for non-smokers on quite a lot of services. The independent airlines are also making progress, so we are moving along. Why the, British Airlines should 
be so resistant is difficult to imagine. What they fail to appreciate is that the sort of figures that $I$ have quoted from the Gallup poll for the community as a whole would almost certainly, if this poll had been restricted to users of the airline services, show an even higher proportion in favour of the extension of non-smoking, because of the known social class difference in smoking habits.

DR BALL: Will air-travellers please always ask for non-smoking seats!

WENDY RiChES (Reader's Digest): I would like to ask Dr Dunwoody a question. I gather ASH have approached BEA, BOAC, buses and trains and other forms of transport; has any approach been made to business firms or institutions about giving up smoking and setting an example?

Dr Dunwoody: We have had some contacts with business and industry. It is a very difficult field to deal with. At the moment most restriction of smoking in industry is for reasons of safety rather than for any other reason and we do know that in some industries experiments have been made in terms of providing a smoking area. Outside that area it is not acceptable to smoke, and there are certain offices where smoking is fairly actively discouraged. I think this is in particular one of the fields where we have got to carry public opinion with us. What one wants is much more pressure building up from office workers for example, who object to having to spend the whole of their working day in a heavily smokecontaminated atmosphere. There is some evidence that there is a slow build-up of opinion, but I think that for us to mount a massive campaign unless we felt we were carrying a lot of people with us, might possibly be counter-productive.

DR T. Defley (Cardiff): A lot of the money that is being saved by the top companies is being spent on putting exotic advertisements in respectable magazines and one is surprised that these magazines are taking them. I picked up a lady's magazine this morning which has nineteen pages on cancer of the breast; it also has six rather exotic pages on advertising smoking! I think that these magazines which take respectable and good adverrisements, are adding an aura of respectability to smoking.

DR Dunwoody: I think it is certainly true that since advertising cigarettes on television was banned in this country about 6 or 7 years ago, there has been a very considerable increase in expenditure on not just advertising but promotion of cigarettes. For example a lot of money is put into coupon schemes and sports sponsorship, and anything indeed that can encourage people to continue to associate smoking with pleasurable and attractive images. As far as press advertisement is con- cerned what we have seen in the past year or two is a very deliberate attempt on the part of the industry to go for those sections of the market where they see a real prospect of improving sales. They seem to be consciously aiming at two areas at the moment. Firstly, as a result of the social class change in the last 15 years or so, we have seen the development of quite a marked social class gradient in terms of cigarette consumption, so those who can least afford it smoke the most and social classes 1 and 2 smoke the least. The example of this is the high proportion of the space in glossy Sunday colour supplements occupied by cigarette advertisements. Secondly, they are aiming at women, because women still smoke significantly less than men do and there are brands designed for women and advertising campaigns geared particularly to the female reader. In part, money is being moved from one area to another; in part, more money is being spent, because the probability is that 60 or 70 million pounds a year are spent on advertising and promotion by the industry at present.

Dr BaLL: Can we for a moment get back to our main topic, which is smoking and the Health service, and this problem of smoking in the wards. I know this is a major problem in many hospitals and there are many hospital physicians here. We have so many smokers come into our ward saying they are grateful for the no-smoking regulation, because it helps them to stop.

DR K. H. Lim (Barnet General Hospital): Are you still carrying out group therapy or hypnosis, individually or in classes, in your anti-smoking clinic?

DR BALL: A number of people are still working on this and we at $\mathrm{ASH}$ are very interested. In fact next month ASH is holding a conference bringing together all those people particularly interested in this to see how its use can be made more effective and more widespread.

DR Howard WiLliams: I don't want to take up any time now, but we have tried both methods. We tried Dr Handel's method at the Chest Clinic with routine advice to patients, and we got $35 \%$ to stop smoking over a period of 6 months. But all these people have chest symptoms and therefore were fair game as far as this advice was concerned. From this point of view there is much more success in general practice if you have got cigarette-related disease; you may have a man who will not listen to advice, but if you find that he is having recurrent chest problems and smokes twenty a day, then he is fair game for advice against smoking. We found the same results as Dr Handel, that females do not stop smoking as well as males. Both at the anti-smoking clinic and also in routine advice at the Chest Clinic it is always the females who come off worse and yet they are the more faithful attenders at the anti-smoking clinic. 